\title{
Superpowerful combined cycle power units with one gas turbine
}

\author{
A. Zaryankin, A. Mager, A. Rogalev \& I. Komarov \\ Moscow Power Engineering Institute, Russia
}

\begin{abstract}
This paper deals with different ways to increase the unit capacity of combined cycle power plants (CCPP) with an in-line equipment layout using a single gas turbine. The transition to a double flow gas turbine using a low-speed low pressure compressor connected with a low-speed steam turbine is a revolutionary way to solve the above problem. The double-shaft compressor is commonly designed with two additional internal bearings and is offered as a solution. The first stages of such a compressor (low pressure compressor (LPC)) connect with the steam turbine, but the second high-pressure group of stages (high-pressure compressor (HPC)) is driven by the gas turbine. So the gas turbine unites a start-up at the base of the HPC. The low pressure compressor and steam turbine can be designed with low revolution speed, which considerably increases air flow through the compressor and leads to an increase in the combined cycle power plant's power capacity.

Keywords: combined cycle power plant (CCPP), gas turbine unit (GTU), air compressor with steam turbine drive, double-flow compressor, additional steam boiler.
\end{abstract}

\section{Introduction}

In Russian thermal power engineering CCPP's are priority guidelines. CCPP combine high efficiency, have a short in-service date and low unit costs of electricity production (compared with the traditional thermal power plants).

In the case of large scale CCPP construction the important economical indicators are the steel intensity and specific capital costs. Both of these indicators are intensively reduced while gas turbine power capacity increases. Nowadays almost all major manufacturers of power gas turbines intensively 
work on the development of heavy-duty gas turbines for CCPP. The characteristics of the modern powerful gas turbine units (GTU) are presented in the table 1. The leading company in the gas turbine design is Mitsubishi. GTU $\mathrm{M} 501 \mathrm{j}$ is the most powerful gas turbine that has ever manufactured. Its' electric power is $\mathrm{N}_{\mathrm{GTU}}=470 \mathrm{MW}$, air flow is $\mathrm{G}=861 \mathrm{~kg} / \mathrm{s}$ and gas inlet temperature equals to $\mathrm{t}_{\text {inlet }}=1600^{\circ} \mathrm{C}$. It should be noted, that the thermal efficiency increases as compared with gas turbine $\mathrm{M} 701 \mathrm{~F} 4$ operating with the gas inlet temperature $1430^{\circ} \mathrm{C}\left(\Delta \mathrm{t}_{\text {inlet }}=170^{\circ} \mathrm{C}\right)$ by $1.1 \%$ only [1]. Power capacity of CCPP based on the turbine M501j is $680 \mathrm{MW}$ and the thermal efficiency reaches $61.7 \%$.

As for equipment layout CCPP may be single-shaft (CCPP with in-line equipment arrangement) or multi-shaft. In the initial stage of CCPP development the most widespread type was multi-shaft. But at present single-shaft units are developed intensively because of their cost, which appears lower by $10-15 \%$ than the multi-shaft CCPP cost. Thus, the progress in heavy-duty gas turbines design will solve the problem of superpowerful CCPP creation on the base of one gas turbine.

There are two types CCPP with in-line equipment arrangement. Thus, in GE scheme gas turbine, compressor, steam turbine and electric generator are linked by one shaft. For such power unit start-up it's required either a very powerful starter or external steam source. This shortcoming is eliminated in the CCPP of Siemens and Alstom, wherein the electric generator connects with the gas turbine rotor and the steam turbine is linked to this shafting through disengaging clutch. In this case when the gas turbine starts the steam turbine can be disconnected from the common shafting. However, application of the disengaging clutch causes a serious increase of shafting length. Increasing CCPP power capacity leads to the growth of the steam turbine rotor length result from the application of the double-flow low-pressure cylinder. Because of this fact

Table 1: Main characteristics of heavy-duty gas turbines.

\begin{tabular}{|l|c|c|c|c|c|c|c|}
\hline & \multicolumn{3}{|c|}{ Mitsubishi } & \multicolumn{2}{c|}{ Siemens } & \multicolumn{2}{c|}{ GE } \\
\cline { 2 - 8 } & $\begin{array}{c}\text { M701 } \\
\text { F4 }\end{array}$ & $\begin{array}{c}\text { M701 } \\
\text { F5 }\end{array}$ & $\begin{array}{c}\text { M501 } \\
\text { J }\end{array}$ & $\begin{array}{c}\text { V94 } \\
\text { 3A }\end{array}$ & $\begin{array}{c}\text { SGT5- } \\
8000 H\end{array}$ & - & $\begin{array}{c}\text { MS } \\
9001 \mathrm{H}\end{array}$ \\
\hline $\begin{array}{l}\text { GTU power capacity, } \\
\text { MW }\end{array}$ & 324.3 & 359 & 470 & 255 & 375 & 255.6 & 330 \\
\hline GTU efficiency, \% & 39.9 & 40 & 41 & 38.5 & $>39$ & 36.9 & 39.5 \\
\hline $\begin{array}{l}\text { Gas inlet } \\
\text { temperature, }{ }^{\circ} \mathrm{C}\end{array}$ & 1430 & 1500 & 1600 & 1315 & - & 1290 & - \\
\hline $\begin{array}{l}\text { Gas outlet } \\
\text { temperature, }{ }^{\circ} \mathrm{C}\end{array}$ & 592 & 611 & 638 & 577 & 625 & 609 & - \\
\hline Air flow, kg/s & 712 & 712 & 861 & 641 & 805 & 645.6 & 670 \\
\hline Compression ratio & 18 & 21 & 23 & 17 & 19.2 & 15.4 & 23.1 \\
\hline $\begin{array}{l}\text { CCPP power } \\
\text { capacity, MW }\end{array}$ & 477.9 & 525 & 680 & 380 & 530 & 390.8 & 520 \\
\hline $\begin{array}{l}\text { Steam turbine power } \\
\text { capacity, MW }\end{array}$ & 324.3 & 359 & 470 & 255 & 375 & 255.6 & 330 \\
\hline CCPP efficiency, \% & 39.9 & 40 & 41 & 38.5 & $>39$ & 36.9 & 39.5 \\
\hline
\end{tabular}


such a scheme application becomes unattractive for powerful CCPPs. Moreover the power start may be realized only with starting the steam boiler or external steam source.

As far as GTU power capacity increases traditional two-shaft power units with two electric generators have better operating characteristics. However, this situation can be changed if the compressor drive is realized by the steam turbine and CCPP has only one electric generator connected with the gas turbine rotor. The offered decision opens the possibility of superpowerful CCPP creation based on a gas turbine with an initial gas temperature lower than $1400^{\circ} \mathrm{C}$.

\section{Combined cycle power plants with double-shaft compressor and in-line equipment arrangement}

The previously mentioned problems connected with heavy-duty gas turbines application in CCPP can be solved at the expense of the passage to CCPP with in-line equipment arrangement that combine advantages of single-shaft installations but without their disadvantages.

The specified purpose can be achieved by using two-shaft air compressor combining, in a common case a low pressure compressor (LPC) and a high pressure compressor (HPC). In the offered CCPP scheme steam turbine is rigidly connected with the low pressure compressor, but the high pressure compressor is driven by the gas turbine, and this useful power is used to drive the electric generator. The HPC rotor and the gas turbine rotor is a single structure. The longitudinal section of a gas turbine with double-shaft compressor is shown in fig. 1.

The passage from the single-shaft to the double-shaft compressor in this case does not break its' initial aerodynamic characteristics because internals changes associate with installing of additional supporting and thrust bearings while keeping the original number of compressor stages and their profiling. Such changes lead to compressor axial length increase. In case of saving the original design of compressor case required for the bearings installation place may be obtained by case cutting in the place of rotor separation into two parts and installing of special spacer with additional bearings in that place. The place of the rotor disconnection is determined by equating the steam turbine capacity and the low pressure compressor power consumption.

Specified conditions are described by the following equation:

$$
N_{S T}=C p_{\text {air }} T_{a} G_{\text {air }}\left(\varepsilon_{1}^{m}-1\right) 1 / \eta_{1 c}
$$

where, $N_{S T}$ - steam turbine capacity; $C p_{\text {air }}$ - air heat capacity; $T_{a}$ - ambient temperature; $G_{a i r}$ - air flow; $\varepsilon_{1}=P_{1} / P_{a}-$ LPC compression ratio ( $P_{l}, P_{a}$ - outlet, inlet air pressure); $m=k-1 / k-$ exponent; $\eta_{l c}$ - LPC efficiency.

Hence:

$$
\varepsilon_{1}=\sqrt[m]{1+\frac{N_{S T} \eta_{1 c}}{C p_{\text {air }} T_{a} G_{\text {air }}}}
$$




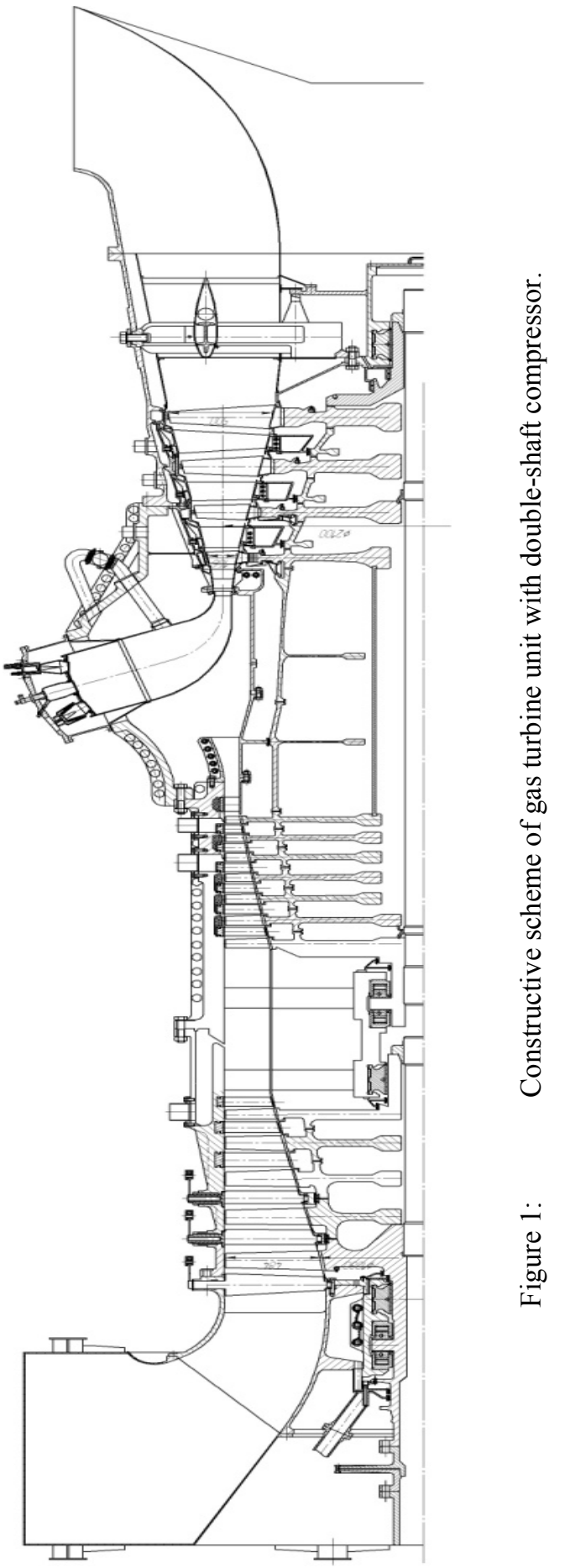


The previously mentioned changes in the scheme of the single-shaft CCPP lead to the following results:

1. CCPP power control considerably improves because separated from the common shafting LPC driving by steam turbine can operate in wide revolution speed range, thereby to change the overall air compression ratio and air flow through the double-shaft compressor.

2. Separation of the steam-turbocompressor unit from the gas turbine can reduce power consumption for GTU start by $40 \%$. The installation startup may be realized without external steam source, which is necessary for the steam turbine start in the GE scheme.

3. In case of the absence of linkages between steam turbine and electric generator its' revolution speed in the rated conditions can be both above and below $50 \mathrm{~Hz}$ depending on the task at hand. The increase of revolution speed allows to reduce the metal content of steamturbocompressor unit, but its reduction allows us to create a compressor with very large performance.

All the proposed design and arrangement changes don't lead to hydraulic resistance increase both on the air and on the gas sides even taking into account flow turning by $90^{\circ}$ about its longitudinal axis after the gas turbine.

It should be noted, that the offered passage from the single-shaft CCPP to two-shaft retains all advantages of single-shaft installations both in capital and operating costs. In addition, important thing in terms of the combined-cycle technologies development is allocation of the low pressure compressor with its steam turbine drive as independent unit, which doesn't connect with the gas turbine. In this case a part of thermal energy generating in the gas turbine combustion chamber (CC) may be redistributed to a steam turbine by means of reducing the air compression ratio and complete steam turbine drive of the air compressor can be realized completely.

\section{Influence of air compression ratio on power capacity and thermal efficiency of combined-cycle power plants}

Gas turbine power capacity and efficiency depend on the air compression ratio. Thus, these characteristics of combined cycle power plants vary greatly in case of air compression ratio changing. Let's consider the dependence of CCPP power capacity and thermal efficiency from the air compression ratio according to characteristics of gas turbine SGT5-4000F [2]. The calculation results are presented in fig. 2 and fig. 3.The base value of air compression ratio $\pi_{c}$ is equal to 17 .

The passage from GTU to CCPP leads to sharply increasing thermal efficiency and dependence of efficiency from air compression ratio changes fundamentally. Decrease of compression ratio from 17 to 8.8 reduces GTU efficiency by $19 \%$. But the same decrease of GTU compression ratio operating as a part of CCPP leads to reduction of the efficiency by $1.2 \%$ only, while power capacity increases by $11.7 \%$. When compression ratio drops to 8.8 compressor 


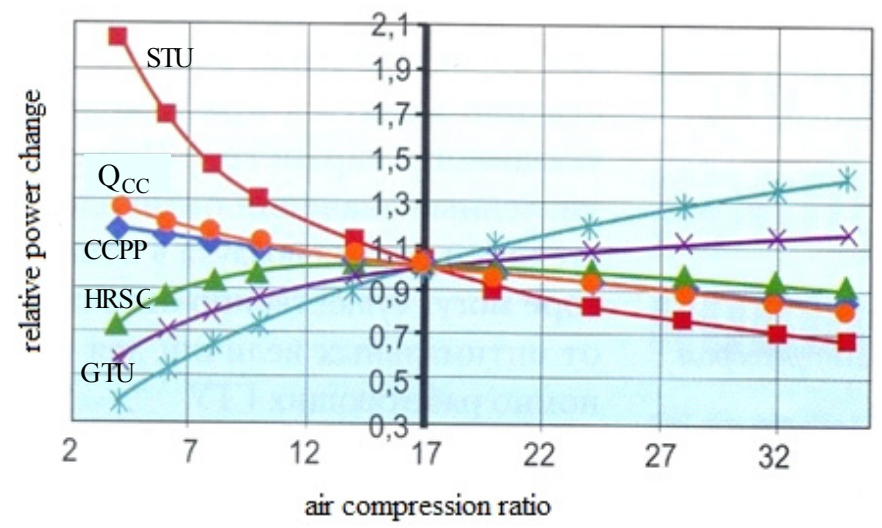

Figure 2: CCPP, GTU, steam turbine unit (STU) and compressor relative power as a function of air compression ratio.

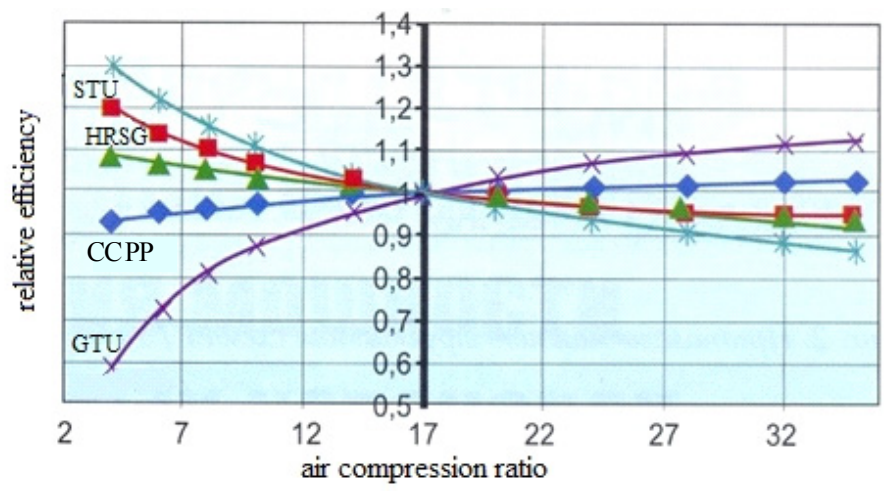

Figure 3: $\quad$ CCPP, GTU, STU, heat recovery steam generator (HRSG) relative efficiency as a function of air compression ratio.

power consumption becomes equal to the steam turbine power capacity. This fact allows for a scheme with a steam turbine drive of the compressor.

The passage to CCPP working on the base of GTU with reduced air compression ratio values and with the same gas inlet temperature as in base GTU leads to a considerable increase of HRSG inlet gas temperature. Thermodynamical analysis of CCPP working on the base of GTU with low initial gas temperature was carried out. The analysis showed, that when initial gas temperatures is less than $1300^{\circ} \mathrm{C}$ the transition to steam turbine drive of the compressor is accompanied not only large increase of CCPP power capacity, but also efficiency growth. Thus, in the CCPP scheme when using a gas turbine with an initial gas temperature equal to $1100^{\circ} \mathrm{C}$ the passage to steam turbine drive of 
the compressor increases efficiency by $4 \%$. Efficiency of CCPP mentioned above becomes equal to efficiency of a CCPP operating with an initial gas temperature of about $1300^{\circ} \mathrm{C}$ [3].

The passage to high temperature steam turbines in CCPP can be realized by usage of extra steam superheater after HRSG. In this case the gas turbine cycle of CCPP remains without any changes.

\section{CCPP with additional power boiler}

Significantly, CCPP power capacity increase may be obtained by extra steam boiler installation. Such a scheme is used in a number of single-shaft CCPP of GE, where a start-up steam boiler is applied. However, the steam capacity of such a boiler is low and it only works when the CCPP starts. A thermal diagram of CCPP with the additional steam boiler is shown in fig. 4 .

In this case CCPP start begins with the start-up of additional steam generator 10 using combustion heat of any fossil fuel for its' operation. Steam from steam generator 10 goes to steam turbine 5, which drives the air compressor 2 . Compressed air ensures gas turbine dry motoring without start-up of combustion chambers. When air compression ratio reaches 3-3.5 the combustion chamber 3 comes into operation and the gas turbine 1 begins to work in no-load operation with further loading. Combustion products from gas turbine enter to HRSG 8 and turn it into operation. For this purpose the shut-off valve 13 and the locking control valve 14 should be opened. Feed water flow going through the regenerative heater 11 and the additional steam generator are regulated by the control valve 12. The additional steam boiler generates steam with the same conditions as in the main cycle. However, in the additional steam cycle regenerative feed water heating is realized by the steam from the steam turbine.

Additional steam generator should provide autonomous operation of steam turbine drive of the air compressor without mechanical connection to the gas turbine. Let's find equation for calculation of the additional steam generator 10

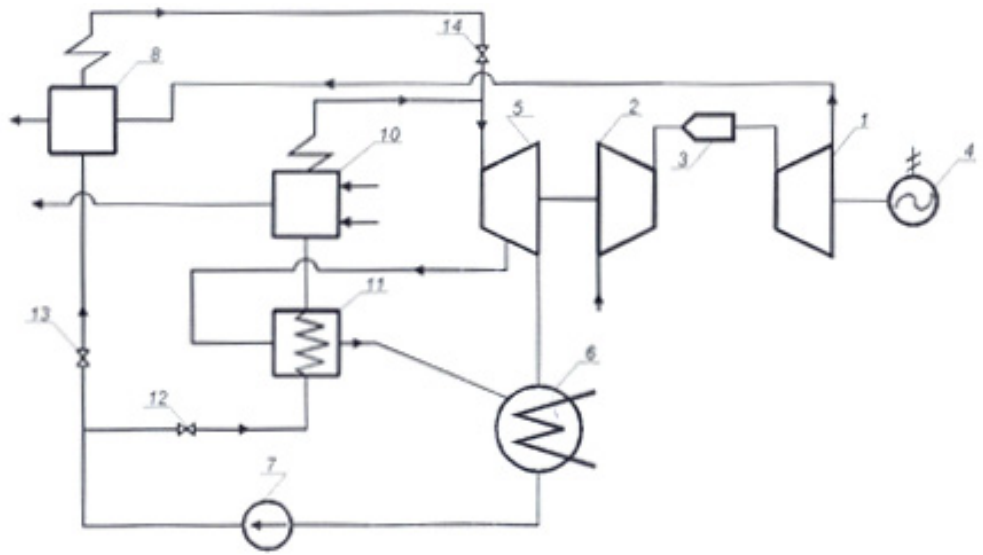

Figure 4: $\quad$ CCPP scheme with additional power boiler. 
steam capacity. The steam turbine power capacity $\mathrm{N}_{\mathrm{ST}}$ and power consumption required to drive the air compressor $\mathrm{N}_{\mathrm{C}}$ are connected with gas turbine power capacity by the following equations:

$$
\begin{gathered}
N_{S T}=b N_{G T}, \\
N_{C}=a N_{G T}
\end{gathered}
$$

where, $N_{G T}$ - gas turbine power capacity; $N_{C}$ - compressor power consumption; $b=0.2 \div 0.25 ; a=0.45 \div 0.5$.

Full compressor drive by steam turbine may be realized in case of steam turbine drive power capacity increasing by an amount $\Delta \mathrm{N}$ equals to the difference between air compressor power consumption $\mathrm{N}_{\mathrm{C}}$ and power capacity of steam turbine $\mathrm{N}_{\mathrm{ST}}$ operating as a part of a conventional CCPP.

That is,

$$
\Delta N=N_{C}-N_{S T}=N_{G T}(a-b) \approx 0,25 N_{G T}
$$

Therefore, the compressor can be separated from gas turbine in case of increase steam turbine capacity by $25 \%$ of the total GTU power capacity. It allows to utilize all gas turbine power for electric generator drive.

Additional boiler steam capacity is determined by a rather simple equation. The additional power $\Delta \mathrm{N}$ associated with additional steam flow is estimated by the following expressions:

$$
\begin{gathered}
\Delta N=G_{S T}^{\circ}\left(h_{0}^{\prime \prime}-h_{z}^{\prime \prime}\right) \eta_{S T} \\
G_{S T}^{\circ}=\frac{\Delta N}{\left(h_{0}^{\prime \prime}-h_{z}^{\prime \prime}\right) \eta_{S T}}
\end{gathered}
$$

According to eqn. (5),

$$
G_{S T}^{\circ}=N_{G T} \frac{(a-b)}{\left(h_{0}^{\prime \prime}-h_{z}^{\prime \prime}\right) \eta_{S T}} \approx \frac{0,25 N_{G T}}{\left(h_{0}^{\prime \prime}-h_{z}^{\prime \prime}\right) \eta_{S T}}
$$

where, $G_{S T}^{\circ}$ - steam flow, generated in additional power boiler; $h_{0}{ }^{\prime \prime}$ - HRSG outlet steam enthalpy; $h_{z}{ }^{\prime \prime}$ - steam enthalpy after the steam turbine last stage; $a=N_{C} / N_{G T} ; b=N_{S T} / N_{G T}$.

The fundamental difference between the offered CCPP and known analogues consists in additional steam cycle realized on the basis of additional boiler (steam generator) operates on the principle of regenerative Rankin cycle, which efficiency is higher by $7-10 \%$ in comparison with cycle without heat regeneration. Power capacity of CCPP based on single GTU can be considerably increased at the expense of application of new double flow gas turbines. Thermal diagram of CCPP with such gas turbine is shown in fig. 5 . 


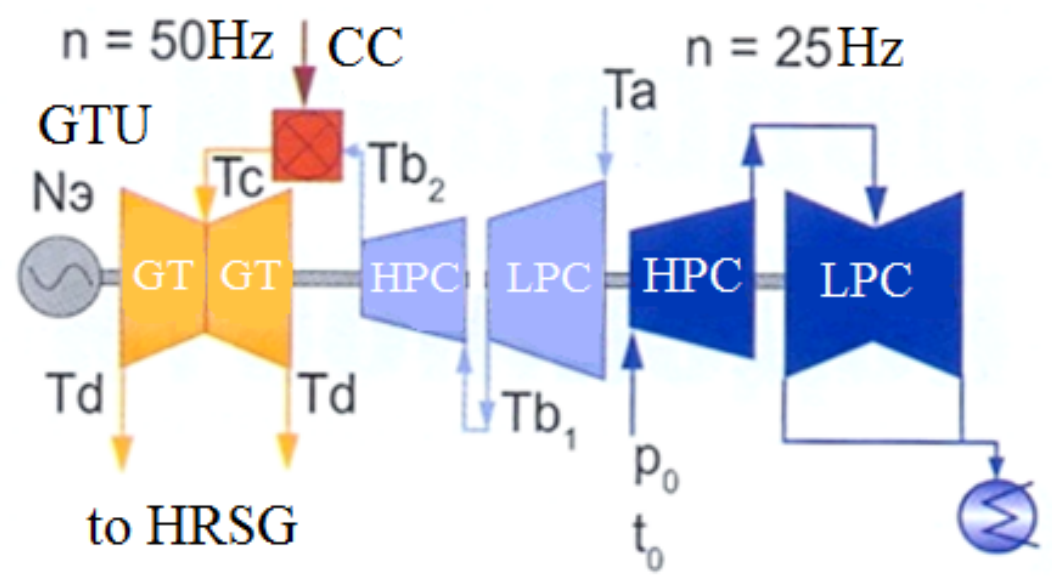

Figure 5: CCPP equipment arrangement with double-flow gas turbine and low speed compressor.

\section{Conclusions}

According to this research we can draw the following conclusions:

a. The investigation shows the utility and possibility of the passage to double-shaft combine cycle power plants in case of equipment in-line arrangement at the expense of double-shaft compressors application, which are designed in a common case. The drive of low-pressure compressor is realized by steam turbine and the high-pressure compressor shaft connects with the gas turbine.

b. The passage to steam turbine drive of low pressure compressor gives an opportunity to realize quantity power level control of gas turbine unites. Moreover connection of low pressure compressor with steam turbine only allows to design this block with lower revolution speed (for instance $1500 \mathrm{rpm}$ ). Such solution gives an opportunity to increase air mass flow and in complex with double-flow gas turbine application allows to considerably increase gas turbine unit maximum power.

c. The analysis of air compression ratio impact on combined cycle power plant capacity shows that if the initial temperature at the gas turbine inlet is lower than $1300^{\circ} \mathrm{C}$ the air compression ration decreasing leads not only to power capacity but also thermal efficiency growth by means of a partial heat energy transfer from gas turbine cycle to steam cycle. In case of initial gas temperature is higher than $1300^{\circ} \mathrm{C}$ the air compression ratio growth results in CCPP power capacity increase but thermal efficiency reduces. 
260 Energy Production and Management in the 21st Century, Vol. 1

\section{References}

[1] Olkhovskiy, G.G. Design of modern heavy-duty gas turbines in Japan. Energeticheskoe hozaystvo za rubezhom, 4, pp. 13-16, 2013.

[2] Kostjuk, A.G., Frolov, V.V., Bulkin, A.E., Truchnij, A.D. Steam and gas turbines for thermal power plants, Moscow: MPEI, 2008.

[3] Zaryankin, A.E., Rogalev, A.N., Mager, A.S. Computational research of power increasing ways of combined cycle power plants with one gas turbine. Gazoturbinnye tehnologii, 4, pp. 40-43, 2013. 